\title{
Synthesis of Cinacalcet Hydrochloride: A Case Study on the Impact of Agitation Speed on the Reaction Kinetics of Schiff's Base during Scale-up
}

\author{
Kunal M. Jagtap ${ }^{a, b}$ \\ Gorakshanath B. Shinde ${ }^{a}$ \\ Navnath C. Niphade ${ }^{a}$ \\ Ashish P. Teldhune ${ }^{a}$ \\ Raghunath B. Toche ${ }^{b}$ \\ Vijayavitthal T. Mathad*a \\ ${ }^{a}$ Department of Process Research and Development, \\ Megafine Pharma (P) Ltd., Plot no. 31 to 35,48 to 51,5,26 \\ and K/201, Lakhmapur, Dindori, Nashik-422 202, Maharash- \\ tra, India \\ vt.mathad@megafine.in \\ drvtmathad@yahoo.co.in \\ b Organic Chemistry Research Center, Department of Chemis- \\ try, KRT Arts, B.H. Commerce and A.M. Science College, \\ Gangapur Road, Nashik-422002, India
}

Megafine Publication Number: MF/33/2017

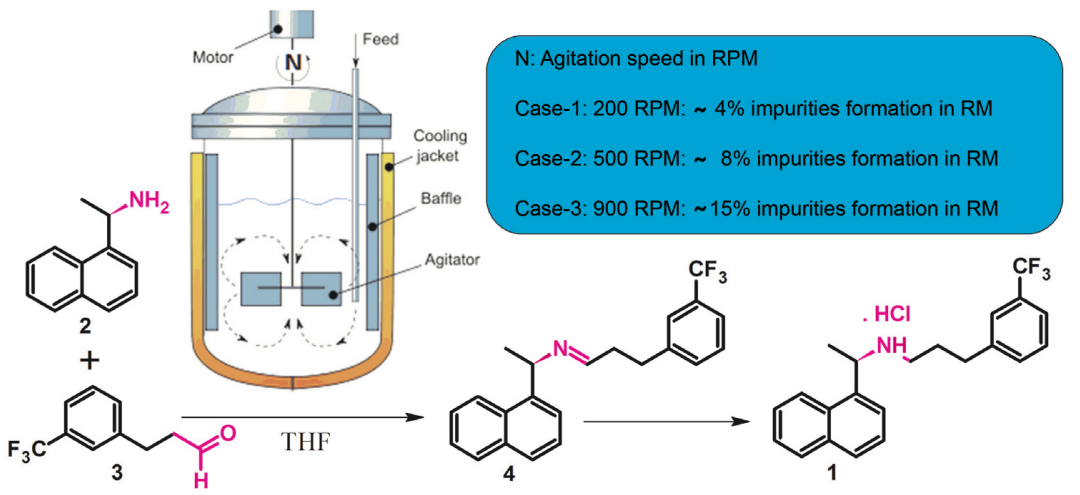

Received: 26.12.2017

Accepted after revision: 10.02 .2018

Published online: 14.03 .2018

DOI: 10.1055/s-0036-1591772; Art ID: so-2017-d0063-I

License terms: CC)

Abstract During the process development of Cinacalcet hydrochloride, a calcimimetic agent, we encountered an unexpected substantial increase in the content of impurities in the product while scaling up the process in the pilot plant. Detailed investigation led to the conclusion that the agitation speed of the reaction mass impacted the reaction kinetics of Schiff's base, leading to the formation of the impurities and lowering the product yield to ca. $40 \%$. The present work reports details of an investigation carried out to control the formation of impurities to achieve an efficient and one-pot process for Cinacalcet hydrochloride with an overall yield of ca. $70 \%$.

Keywords Cinacalcet, calcimimetic drug, agitation speed, reaction kinetics, Schiff's base, tips speed, scale-up

\section{Introduction}

Pharmaceutical process scale-up is a challenging task, as the smooth transition of chemical process developed at laboratory scale to pilot and subsequently to production scale depends on the systematic optimization of reaction parameters such as mole ratio, reaction solvent, time, temperature, mode of addition and right choice of physical and mechanical conditions with respect to agitation pattern and speed, type and make of reaction vessels etc. Successful scale-up of a process is dependent on the design and linkage of each unit parameter with every other parameter to provide a synergic result. Both chemists and chemical engineers strive to design a reliable process for production scale by identifying the most prominent reaction parameters, understanding the role and impact of both chemical and physical processes at different scales affecting the quality and yields. ${ }^{1}$ Achieving this first time using the laboratory scale data at commercial scale is difficult; hence, pilot studies conducted between the two provides an opportunity to gain sufficient insight into all chemical, physical and mechanical conditions. Mixing of the reaction components in a reaction vessel is an important parameter that determines the rate of a chemical reaction. A production mixing unit is usually not geometrically similar to the mechanical stirrer used in the laboratory. Such differences can make scale-up from the laboratory or pilot plant challenging. A solution to these problems is to systematically calculate and evaluate mixing characteristics applicable to the scale basis laboratory data. ${ }^{2}$ In this article, we report how agitation speed of the reaction mass impacted the reaction kinetics of formation of Schiff base (4) during the synthesis of Cinacalcet hydrochloride (1).

Cinacalcet hydrochloride (1), the first drug in the class of calcimimetics, is approved by the United States Food and Drug Administration as Sensipar ${ }^{\circledR}$ and Mimpara ${ }^{\circledR}$. Calcimimetics belong to a class of orally active, small molecules that decrease the secretion of parathyroid hormone (PTH) by activating calcium receptors, and they are used for the treatment of hyperparathyroidism (HPT). ${ }^{3}$

Original synthetic methods ${ }^{4}$ (Path 1, Scheme 1) developed for synthesis of $\mathbf{1}$ were based on reductive amination approaches using titanium isopropoxide and diisobutylaluminum hydride (DIBAL-H) or sodium cyanoborohydride. These reported methods employed chiral chromatographic techniques to purify Cinacalcet hydrochloride, which are not feasible on an industrial scale. In recent years, extensive efforts have also been made towards the development of ef- 


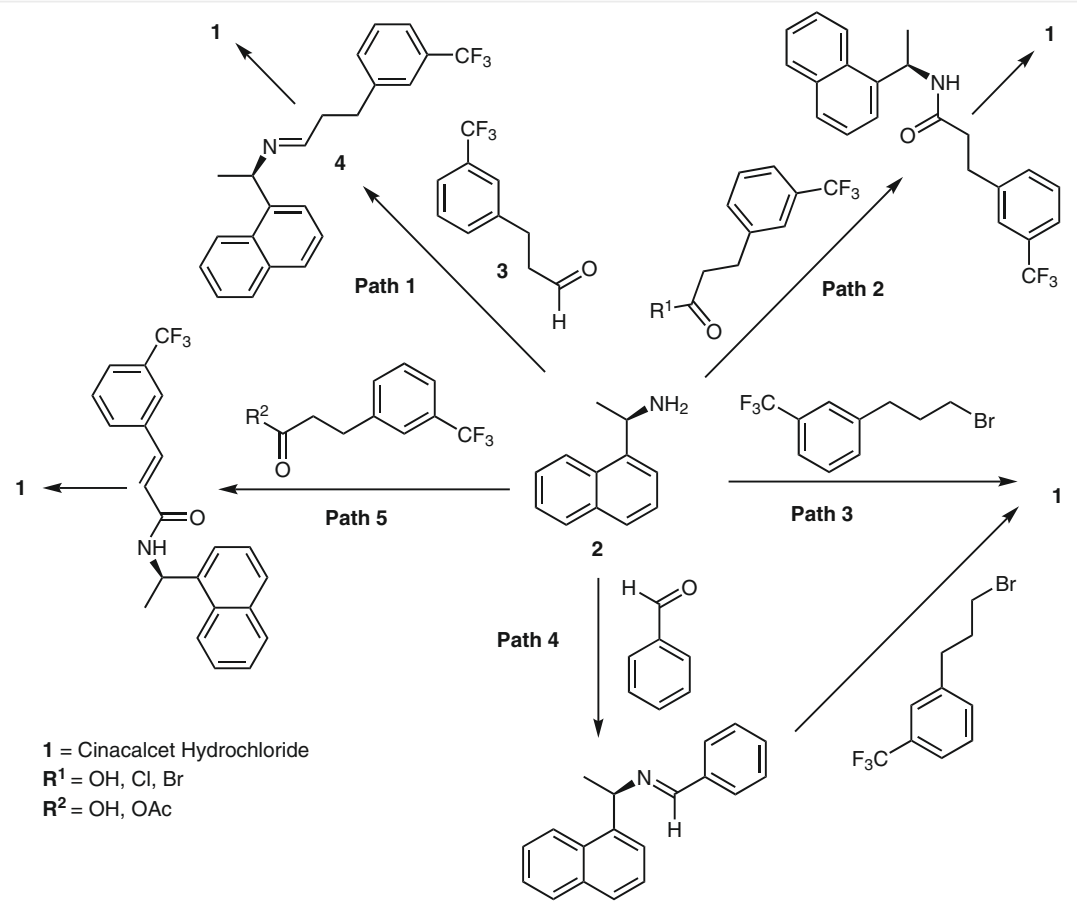

Scheme 1 Reported approaches for the preparation of Cinacalcet hydrochloride (1)

ficient synthetic methods for $\mathbf{1}^{5}$ (Path 2, 3, 4 and 5, Scheme 1 ); however, few of the approaches offer improved scalability over the first-generation syntheses including one from our laboratory using Froster's reaction.

Many other methods using different synthetic strategies such as coupling reactions with different starting materials were also reported but are not industrially feasible. ${ }^{6}$

To provide a simple, efficient, one-pot and economic process for the industrial preparation of Cinacalcet, we have taken up its development. Based on the easy availability of key starting materials (2 and 3) and ease of synthesis, we developed an efficient process for making $\mathbf{1}$ by following the path 1 of Scheme 1, wherein amine 2 is condensed with aldehyde 3 to form (1R)-1-(1-naphthyl)- $N-\{(1 E)-3-[3-$ (trifluoromethyl)phenyl]propylidene\}ethanamine [Schiff's base (imine)] (4) followed by reductive amination of the obtained 4 in the same pot to provide Cinacalcet hydrochloride (1) with overall yield of ca. $70 \%$ and purity of $99.5 \%$ by HPLC. While optimizing the laboratory established parameters at pilot scale, we made an unusual observation of substantial increment in the content of impurities $(\mathbf{5}, \mathbf{6}$, and $\mathbf{7})$ in the product by more than twofold, thereby lowering the yield of $\mathbf{1}$ and affecting the process economics substantially.

\section{Results and Discussion}

The key intermediate amine $\mathbf{2}$ was synthesized by using a recently reported improved process, ${ }^{7}$ and the synthesis of aldehyde intermediate $\mathbf{3}$ was accomplished at scale by using pyridinium chlorochromate (PCC) mediated oxidation of alcohol established in our laboratory. ${ }^{8,9}$ The preparation of $\mathbf{1}$ was established by reacting $\mathbf{2}$ with $\mathbf{3}$ in tetrahydrofuran (THF) at room temperature to furnish Schiff's base (4) as an oil, which was then subjected to reductive amination to give Cinacalcet hydrochloride (1). During feasibility studies in the laboratory, $\mathbf{4}$ and $\mathbf{1}$ were synthesized and optimized separately; however, the isolated oil of $\mathbf{4}$ was found to be unstable upon storage for a longer period under atmospheric conditions. Hence, we telescoped the synthesis of $\mathbf{4}$ and $\mathbf{1}$ in one pot by conducting reductive amination of $\mathbf{4}$ in the same pot using sodium triacetoxyborohydride $\left[\mathrm{NaBH}(\mathrm{OAC})_{3}\right]$ in $\mathrm{THF}$ at room temperature. The reaction mass of 1 was then treated with water and aqueous $\mathrm{HCl}$ followed by the usual workup procedure to furnish $\mathbf{1}$ as a white crystalline solid with an overall yield of ca. 70\% and purity of $99.9 \%$ by HPLC (Scheme 2 ).

Isolation and identification of impurities during development: While optimizing the one-pot process for $\mathbf{1}$, the reaction mass was analyzed as a part of reaction monitoring to understand the progress of reaction. Three unknown peaks were identified at RRT $1.58,1.63$ and 1.85 at a level of ca. $4-5 \%$ in the HPLC plot. After work-up and isolation, one impurity (at RRT 1.85) of the three impurities remained at a level of $0.3 \%$ in crude $\mathbf{1}$ and less than $0.10 \%$ in pure 1 after crystallization. The molecular mass of these unknown peaks were recorded using LC-MS techniques and probable structures were predicted based on the molecular weights. Molecular mass of $560\left[\mathrm{M}^{+}+1\right], 542\left[\mathrm{M}^{+}+1\right]$, and $544\left[\mathrm{M}^{+}+1\right]$ were recorded for the peaks observed at RRT 


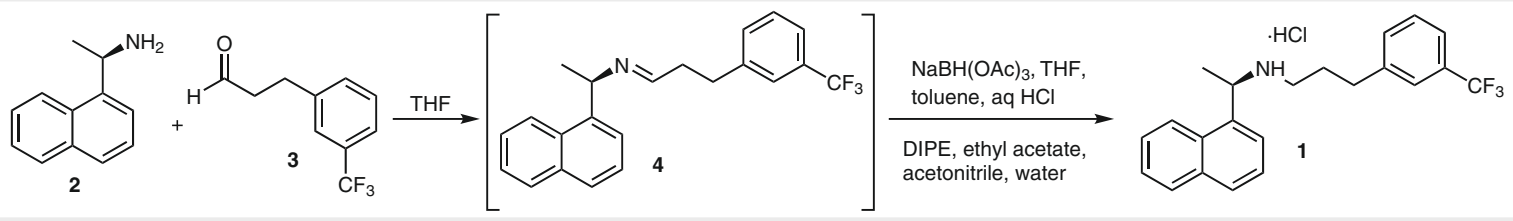

Scheme 2 Synthetic path of Cinacalcet hydrochloride (1)

$1.58,1.63$ and 1.85 , respectively. Two peaks observed at RRT 1.58 and 1.63 were absent in isolated crude $\mathbf{1}$, but the peak corresponding to molecular weight 544 (RRT of 1.85) remained in crude $\mathbf{1}$ at around $0.3 \%$. Based on the difference between molecular masses of $\mathbf{1}\left(357,\left[\mathrm{M}^{+}\right]\right)$and impurity at RRT 1.85 (544, $\left.\left[\mathrm{M}^{+}+1\right]\right)$, the structure 7, having di-substitution at nitrogen atom, was predicted (Scheme 3). Furthermore, the molecular structures of the unknown peaks observed at RRT 1.58 and 1.63 were also predicted as compounds $\mathbf{5}$ and $\mathbf{6}$ based on molecular masses and on the structure of compound 7. Subsequently, the proposed impurity at RRT 1.85 was synthesized, characterized, and confirmed based on spectroscopic and chromatographic data as di-alkyl impurity 7 of Cinacalcet.

To understand the basis for the formation of $\mathbf{7}$, we presumed that the excess mole ratio of $\mathbf{3}$ with respect to $\mathbf{2}$ can lead to the over-alkylation of $\mathbf{1}$, thereby resulting in the formation of 7. To evaluate our hypothesis, experiments were conducted in laboratory with varied mole ratio of $\mathbf{3}$ with respect to $\mathbf{2}$ on the formation of 7; the results are captured in Table 1. Based on the experimental data, a slight excess mole ratio of $\mathbf{3}$ with respect to $\mathbf{2}$ (1.06 mole equiv instead of 1.0 mole equiv) led to a substantial increase in the formation of 7 (Table 1, entries 8 and 9); thus, the process was finalized using 1.0 mole equiv of 3 with respect to 2 to achieve the desired results (Table 1, entry 1 ). After optimizing the process with respect to other process parameters in the laboratory (Lab), three batches were executed in the pilot plant (PP) at 1-3 kg levels to check the scalability of the process; surprisingly, it was observed that the yield obtained for all the three batches were lower than the expected yields by almost $30 \%$.

Investigation for low yield of $\mathbf{1}$ in the pilot scale: As a part of our investigation, we reviewed the HPLC chromatograms of the reaction mass analyzed under in-process control check (IPC) and found that the quantity of $\mathbf{1}$ formed in the reaction mass was ca. $47 \%$ against the expected range of 75-80\%, unreacted amine 2 was ca. 13\% against the expected range of $5-7 \%$, and the amounts of impurities $\mathbf{5}, \mathbf{6}$, and 7 were found to be higher by ca. $14 \%$ against the expected range of ca. $4 \%$ compared to the laboratory data. Subsequent workup and isolation indicated that the established downstream procedure and purification process was capable of removing these impurities along with unreacted amine $\mathbf{2}$ from $\mathbf{1}$ but the yield of $\mathbf{1}$ highly impacted the economics of the process. Thus, we initiated a detailed investi-

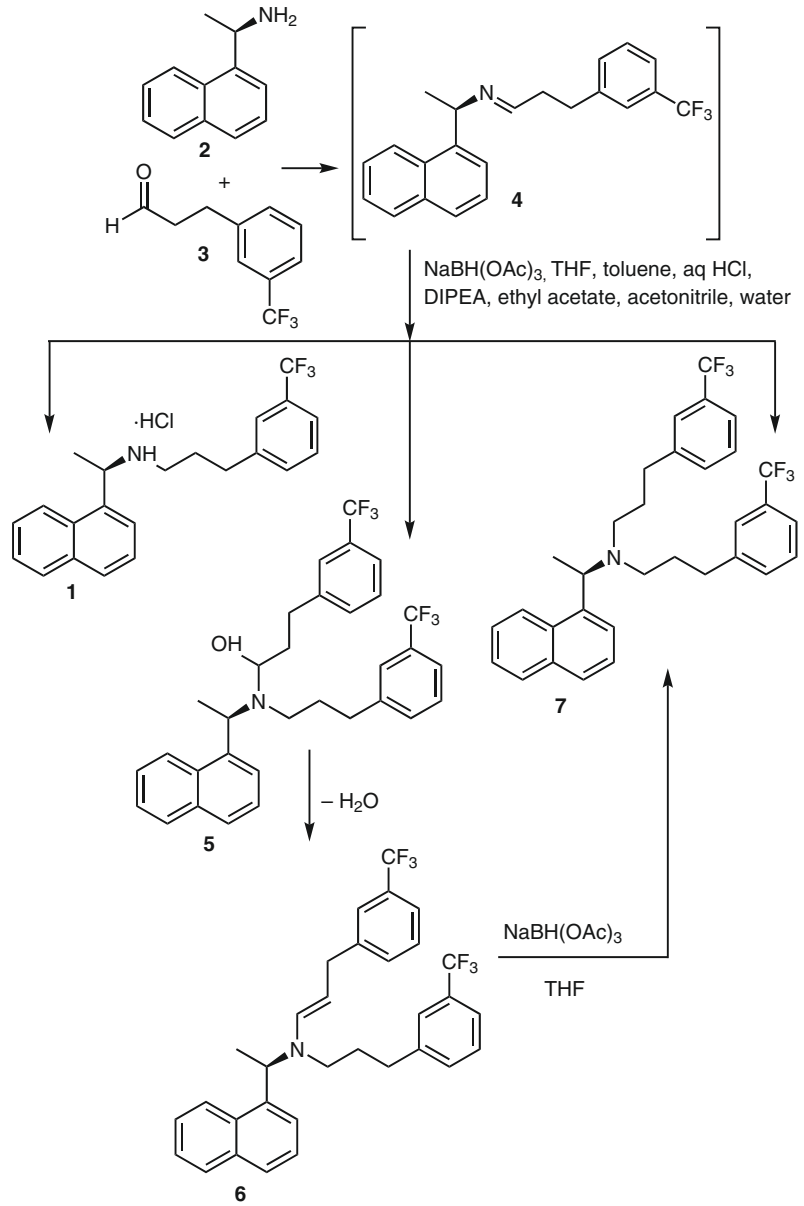

Scheme 3 Possible pathway for formation of di-alkyl impurity in Cinacalcet hydrochloride

gation to identify the root cause of the increased content of impurities in $\mathbf{1}$ at the pilot plant batches and establish a mechanism to control and/or eliminate the impurities accordingly to obtain $\mathbf{1}$ at production scale as per $\mathrm{ICH}^{10}$ norms.

Probable reason for formation of Impurities: During the investigation, we checked for possible differences that could have led to this deviation during scale-up, but could not detect any direct evidence for the failure. Based on the laboratory data, we assumed the following reasons as probable cause for this failure: (a) mole ratio of $\mathbf{3}$ with respect to $\mathbf{2}$, (b) agitation speed of the reactor, and (c) mode of addition of $\mathbf{2}$ and $\mathbf{3}$. 
(a) Mole ratio of 3 with respect to 2: Based on the learnings in the laboratory, we checked for the possibility of over-alkylation leading to the increased formation of the impurities due to the presence of the high concentration of the aldehyde molecules $\mathbf{3}$ in reaction mass, as $\mathbf{2}$ was added to the bulk of $\mathbf{3}$ in the reactor. It was found that the mole ratio of 3 with respect to 2 was as per requirement (1.0 mole equiv), hence, we negated our hypothesis of the impact of the mole ratio on the formation of these impurities.

(b) Agitation speed of the reactor: The agitation speed determines the rate of mixing, which, in turn, affects the rate of reaction. The agitation speed, in revolutions per minute (RPM) required to be maintained at scale was suspected as the reason for the above failure. As a part of investigation, we therefore evaluated the deviation, if any, in the agitation speed (i.e., RPM) used in the laboratory and during pilot plant batch using Equation (1):

$N=V / \pi \times D$ (Eq. 1$)$

where $N$ is the number of revolutions per second, $V$ is the velocity, $\pi$ is the physical constant (3.14), and D is the diameter of the blade in meters. Accordingly, we calculated the velocity $(V)$ of laboratory batches as follows:

$\mathrm{V}=\pi \times D \times N=3.14 \times 0.1 \times 3.33=1.046 \mathrm{~m} / \mathrm{s}$

(where $N=200 \mathrm{rev} / \mathrm{min}=3.33 \mathrm{rev} / \mathrm{sec}$, and $D=0.1 \mathrm{~m}$ ).

Based on the above data generated from the laboratory batches, the TIPS speed required to be used for pilot batches has been calculated using Eq. (1):

$N=1.046 / 3.14 \times 0.50=0.666 \mathrm{rev} / \mathrm{sec}=39.97 \mathrm{rev} / \mathrm{min}$

(where the diameter of scale-up reactor $D=0.50 \mathrm{~m}$ )

With this data in hand, we have checked for the RPM followed during the pilot batches and found it to be 70 RPM, which is almost double compared with the required RPM of 40 , and thus agitation speed was considered as one of the major root causes for the erratic results.
To confirm the above hypothesis, we designed and conducted experiments in both the laboratory and in pilot plant at kilogram scale concurrently with varied RPM and collected sufficient analytical details on the formation of impurities, consumption of starting materials in reaction mass, time at which impurities formed, and their fate throughout isolation of $\mathbf{1}$ (Table 1 ).

According to data obtained from experiments, 200 RPM during laboratory reaction and 40 RPM (equivalent to 200 RPM of laboratory batch) during pilot plant reaction showed comparable yields and purity of $\mathbf{1}$ (Table 1, entries 1 , and 4), indicating similar reaction progress. Furthermore, the reactions conducted in laboratory with fast agitation (i.e., 500 and 950 RPM) to understand the impact of high stirring speed on the reaction kinetics showed substantial increase (ca. 8-11\%) in the formation of impurities 5, 6, and 7 (Table 1, entries 2 and 3). The data of the original pilot plant batch was also included in the table (Table 1, entry 5) to compare the data obtained at 70 RPM. Based on the data, it can be concluded that the increase in the agitation speed results in an increase in the reaction kinetics, thereby leading to the increased content of $\mathbf{5 , 6}$, and $\mathbf{7}$ in $\mathbf{1}$.

(c) Mode of addition of 2 and 3: The established process finalized in the laboratory involved slow addition of amine $\mathbf{2}$ into a solution of aldehyde $\mathbf{3}$, wherein a molecule of amine $\mathbf{2}$ can be exposed to the bulk of aldehyde $\mathbf{3}$, which may result in the formation of an increased amount $\mathbf{5}$ that can subsequently be converted into $\mathbf{6}$, which is then converted into di-alkyl impurity $\mathbf{7}$. We presumed that changing the mode of addition may reduce the extent of impurity formation at scale. To confirm our hypothesis, aldehyde $\mathbf{3}$ was slowly added to a solution of amine $\mathbf{2}$ keeping agitation speed 200 RPM and 40 RPM at laboratory and pilot plant batch, respectively. The outcomes of the batch reactions were similar to those of obtained with the previous addi-

Table 1 Influence of Agitation on Reaction Kinetics of Laboratory and Scale-up Batches

\begin{tabular}{|c|c|c|c|c|c|c|c|c|}
\hline \multirow[t]{2}{*}{ Entry No. } & \multirow{2}{*}{$\begin{array}{l}\text { Source of } \\
\text { batch }\end{array}$} & \multirow[t]{2}{*}{ Input 3 (g) } & \multirow{2}{*}{$\begin{array}{l}\text { Mole ratio of } \mathbf{3} \\
\text { w.r.t. } \mathbf{2}\end{array}$} & \multirow{2}{*}{$\begin{array}{l}\text { Agitation speed } \\
\text { (RPM) }\end{array}$} & \multirow[t]{2}{*}{ Yield of $1(\%)$} & \multicolumn{3}{|c|}{ Reaction monitoring by HPLC (\%) } \\
\hline & & & & & & 1 & 2 & $5+6+7$ \\
\hline 1 & Lab & 100 & 1.0 & 200 & 69.33 & 80.84 & 6.60 & 4.28 \\
\hline 2 & Lab & 100 & 1.0 & 500 & 60.33 & 69.50 & 6.60 & 7.90 \\
\hline 3 & Lab & 100 & 1.0 & 950 & 49.87 & 62.00 & 7.29 & 10.51 \\
\hline 4 & PP & 1000 & 1.0 & 40 & 70.36 & 79.38 & 6.56 & 5.25 \\
\hline 5 & PP & 1900 & 1.0 & 70 & 43.24 & 46.54 & 13.32 & 13.81 \\
\hline $6^{\mathrm{a}}$ & Lab & 200 & 1.0 & 200 & 69.33 & 80.84 & 6.60 & 4.28 \\
\hline $7^{\mathrm{a}}$ & PP & 1000 & 1.0 & 40 & 68.25 & 78.72 & 6.06 & 6.01 \\
\hline 8 & Lab & 100 & 1.06 & 200 & 51.36 & 69.33 & 5.67 & 9.23 \\
\hline 9 & PP & 650 & 1.06 & 40 & 54.0 & 72.46 & 4.73 & 9.30 \\
\hline
\end{tabular}

a Compound $\mathbf{3}$ was added to 2 . 
tion sequence (Table 1, entries 6 and 7). Hence, we conclude that mode of addition of $\mathbf{2}$ and $\mathbf{3}$ has no impact on the increased amount of impurities.

To understand the role of the mole ratio of $\mathbf{3}$ and $\mathbf{2}$, we additionally designed and conducted one experiment in laboratory and one in the pilot plant at kilogram scale concurrently, wherein 1.06 mole equivalents of $\mathbf{3}$ with respect to 2 were added instead of 1.0 mole, keeping agitation speed 200 RPM for laboratory experiment and 40 RPM for scale-up experiment. The data indicated that both the mole ratio and stirring have great influence on the rate of the reaction as they resulted in increased formation of impurities $\mathbf{5 , 6}$ and $\mathbf{7}$ at levels of ca. 9.0\% in both cases (Table 1, entries 8 and 9 ).

Preventive actions for avoiding the failure at production scale: Based on the outcome of the above investigation it was decided to implement the following during scale-up batches: (a) agitation speed (RPM) of the reactor of the pilot plant should be reduced to 40 RPM based on the tips speed, and (b) mole ratio of $\mathbf{3}$ was restricted to not more than 1.0 mole equivalent with respect to $\mathbf{2}$ to control the formation of impurities 5, 6, and $\mathbf{7}$ in the reaction.

\section{Conclusion}

Detailed investigations performed to address the issue that appeared during the scale-up revealed that the higher amounts of impurities formed in the scale-up batch was proportional to the extent of agitation, indicating the dependence of reaction kinetics on the stirring speed. Laboratory batches were studied in detail to determine the agitation speed, wherein the tips speed was calculated. The findings were implemented in the scale-up process to achieve expected yields and purity of 1 .

In summary, we have investigated the factors responsible for failure of the pilot plant batch of Cinacalcet hydrochloride (1) and accordingly established a single-pot process suitable for use at scale that generates the desired purity and yield.

Melting points were determined with an Analab melting point apparatus, in open capillary tubes and are uncorrected. ${ }^{1} \mathrm{H}$ NMR (400 $\mathrm{MHz})$ and ${ }^{13} \mathrm{C}$ NMR $(100 \mathrm{MHz})$ spectra were recorded with a Varian Gemini $400 \mathrm{MHz}$ FT NMR spectrometer. Chemical shifts are reported in parts per million (ppm) using tetramethylsilane as internal standard and are given in $\delta$ units. The solvents for NMR spectra were deuterochloroform and deuterodimethylsulfoxide unless otherwise stated. Infrared spectra were taken with a Perkin Elmer Spectrum 100 in potassium bromide pallets unless otherwise stated. Elemental analyses were performed with a Hosli $\mathrm{CH}$-Analyzer and the results were within $\pm 0.3 \%$ of the calculated values. High-resolution mass spectra were obtained with a Shimadzu GC-MS QP mass spectrometer with an ionization potential of $70 \mathrm{eV}$. All the reaction were monitored by thin-layer chromatography (TLC), carried out on $0.2 \mathrm{~mm}$ silica gel
60F254 (Merck) plates using UV light (254 and $366 \mathrm{~nm}$ ) or high-performance liquid chromatography (HPLC) with Agilent Technologies 1200 series for detection. Gas chromatography with Agilent Technologies 7683B with head space was used to analyze the residual solvents. Common reagent-grade chemicals are either commercially available (used without further purification) or were prepared by standard procedures.

\section{Preparation of Cinacalcet Hydrochloride (1); Laboratory Experi- ment at 200 RPM}

To a stirred solution of 3-[3-(trifluoromethyl)phenyl]propanal (3; $100.0 \mathrm{~g}, 0.49$ mole $)$ in THF lot- $1(100 \mathrm{~mL})$ was added a solution of (1R)-1-(1-naphthyl)ethanamine (2; $84.7 \mathrm{~g}, 0.49$ mole) in THF lot-2 $(100 \mathrm{~mL})$ with stirring rate of $200 \mathrm{RPM}$ at $15-20^{\circ} \mathrm{C}$ and the reaction mass was stirred at the same RPM for $90 \mathrm{~min}$. After formation of intermediate compound $\mathbf{4}$ monitored by HPLC, sodium triacetoxy borohydride solution [ $207 \mathrm{~mL}$ of acetic acid was added in solution of 39.90 $\mathrm{g}(0.79$ mole $)$ of $\mathrm{NaBH}_{4}$ in $500 \mathrm{~mL}$ of THF] was added to the reaction mass. The resultant reaction mass was maintained at $20-30{ }^{\circ} \mathrm{C}$ for $2-$ $3 \mathrm{~h}$ with stirring rate of $200 \mathrm{RPM}$. After completion of the reaction monitored by HPLC, reaction mass was diluted with water $(1500 \mathrm{~mL})$, toluene $(1000 \mathrm{~mL})$ and the $\mathrm{pH}$ of the reaction mass was adjusted to 0 1 using aqueous hydrochloric acid. The solution was stirred and layers were separated. The toluene layer was washed with $5 \%$ sodium chloride solution $(500 \mathrm{~mL})$ followed by concentration of the organic solvent under reduced pressure to yield a thick syrup. The obtained syrup was diluted with diisopropyl ether $(500 \mathrm{~mL})$ and the precipitated solid was filtered to obtain $\mathbf{1}$ as a solid. The obtained solid of $\mathbf{1}$ was further suspended in EtOAc $(400 \mathrm{~mL})$, heated at $55-60{ }^{\circ} \mathrm{C}$, cooled to r.t., and the obtained product was filtered to give crude $\mathbf{1}$. The latter was further recrystallized in a mixture of acetonitrile and water $(2: 10,1200 \mathrm{~mL})$ to give pure $\mathbf{1}$ as crystalline solid.

Yield: $135.0 \mathrm{~g}$ (69.40\%); HPLC purity: 99.95\%; chiral purity: 99.95\%. MS: $m / z=358.79\left[\mathrm{M}^{+}+1\right]$.

${ }^{1} \mathrm{H}$ NMR (DMSO- $d_{6}$ ): $\delta=10.12(\mathrm{~s}, 1 \mathrm{H}), 9.43(\mathrm{~s}, 1 \mathrm{H}), 8.26$ (d, $\left.1 \mathrm{H}\right), 8.08$ (d, $1 \mathrm{H}), 8.03-7.99(\mathrm{~m}, 2 \mathrm{H}), 7.63-7.60(\mathrm{~m}, 3 \mathrm{H}), 7.54-7.53(\mathrm{dt}, 2 \mathrm{H})$, 7.48-7.45 (dt, $2 \mathrm{H}), 5.32(\mathrm{q}, 1 \mathrm{H}), 2.96-2.93(\mathrm{~m}, 1 \mathrm{H}), 2.74-2.69(\mathrm{t}$, $3 \mathrm{H}), 2.07-1.97$ (m, $2 \mathrm{H}), 1.71-1.68$ (d, $3 \mathrm{H})$.

\section{Preparation of Cinacalcet Hydrochloride (1); Scale-up Experiment in Pilot Plant at 40 RPM}

To a stirred solution of 3-[3-(trifluoromethyl)phenyl]propanal (3; 1.0 $\mathrm{kg}, 4.94 \mathrm{~mole})$ in THF lot-1 $(1.0 \mathrm{~L})$ was added a solution of $(1 R)-1-(1-$ naphthyl)ethanamine $(2 ; 0.847 \mathrm{~kg}, 4.94$ mole $)$ in THF lot-2 $(1.0 \mathrm{~L})$ with stirring rate of $40 \mathrm{RPM}$ at $15-20^{\circ} \mathrm{C}$ and the reaction mass was stirred at the same RPM for $90 \mathrm{~min}$. After formation of intermediate compound 4 monitored by HPLC, sodium triacetoxy borohydride solution [2.07 $\mathrm{L}$ of acetic acid was added in solution of $399.0 \mathrm{~g} \mathrm{(0.79}$ mole) of $\mathrm{NaBH}_{4}$ in $5.0 \mathrm{~L}$ of THF] was added to the reaction mass. The resultant reaction mass was maintained at $20-30{ }^{\circ} \mathrm{C}$ for $2-3 \mathrm{~h}$ with stirring rate of $40 \mathrm{RPM}$. After completion of the reaction monitored by HPLC, reaction mass was diluted with water $(15.0 \mathrm{~L})$, toluene $(10.0 \mathrm{~L})$ and the $\mathrm{pH}$ of the reaction mass was adjusted to $0-1$ by using aqueous hydrochloric acid. The solution was stirred and layers were separated. The toluene layer was washed with $5 \%$ sodium chloride solution (5.0 L) followed by concentration of organic solvent under reduced pressure to yield a thick syrup. The obtained syrup was diluted with diisopropyl ether $(5.0 \mathrm{~L})$ and the precipitated solid was filtered to obtain 1 as a solid. The latter was further suspended in EtOAc $(4.0 \mathrm{~L})$, heated at $55-60{ }^{\circ} \mathrm{C}$, cooled to r.t., and the obtained product was filtered to give 
crude 1 . The latter was further recrystallized in a mixture of acetonitrile and water $(2: 10,12.0 \mathrm{~L})$ to give pure Cinacalcet hydrochloride as crystalline solid.

Yield: $1.365 \mathrm{~kg}$ (70.17\%); mp $110.2-110.8^{\circ} \mathrm{C}$; HPLC purity: $99.89 \%$; chiral purity: $99.90 \%$.

\section{Acknowledgment}

The authors are grateful to the management of Megafine Pharmaceuticals (P) Ltd., for supporting this work. We also thank colleagues of the Analytical Research and Development Department, Megafine Pharmaceuticals (P) Ltd., for valuable cooperation in developing the chromatographic methods for establishing the process and identifying the impurities. Special thanks go to Ms. Laxmi G. Rao for her valuable input while preparing and finalizing this manuscript.

\section{References}

(1) (a) Zlokarnik, M. In Dimensional Analysis and Scale-up in Chemical Engineering; Springer-Verlag: Berlin, Heidelberg, 1991, 5-22. (b) Bisio, A.; Kabel, R. L. Scale-up of Chemical Processes: Conversion from Laboratory Scale Tests to Successful Commercial Size Design, 1st ed.; Wiley: New York, 1985, 699.

(2) David S. D.; Don't Get Mixed up by Scale-Up, in Chemical Processing; 2005, 81-100

(3) (a) Herbert, S. C. Annu. Rev. Med. 2006, 57, 349. (b) Sorbera, L. A.; Castaner, R. M.; Bayes, M. Drugs Future 2002, 27, 831. (c) Franceschini, N.; Joy, M. S.; Kshirsagar, A. Expert Opin. Invest. Drugs 2003, 12, 1413.

(4) (a) Nemeth, E. F.; Van Wagenen, B. C.; Balandrin, M. F.; delMar, E. G.; Moe, S. T. US Patent US 6011068, 2000; Chem. Abstr. 2001, 135, 352750. (b) Van Wagene, B. C.; Balandrin, M. F.; Delmar, E. G.; Nemeth, E. F. US Patent US 6211244, 2001; Chem. Abstr. 2001, 134, 280612. (c) Wang, X.; Chen, Y.; Crockett, R.; Briones, J.; Yan, T.; Orihuela, C.; Zhi, B. Tetrahedron Lett. 2004, 45, 8355.
(5) (a) Padi, P. R.; Akrundi, S. P.; Suthrpu, S. K.; Kolla, N. K. PCT Appl. WO 2008058235, 2008; Chem. Abstr. 2008, 148, 561587. (b) Oliver, T.; Charles, B.; Robert, L.; John, M. M.; Tamim, R. M. PCT Appl. WO 2009002427, 2009; Chem. Abstr. 2008, 150, 98009. (c) Revital, L. L.; Amihai, E.; Shlomit, W.; Sharon, A.; Yuriy, R.; Revital, R. PCT Appl. WO 2006125026, 2006; Chem. Abstr. 2006, 146, 7705. (d) Gorakshanath, B. S.; Navnath, C. N.; Shrikant, P. D.; Raghunath, B. T.; Vijayavitthal, T. M. Org. Process Res. Dev. 2011, 15, 455.

(6) Marta, B. X.; Rosana, L.; Carmen, E.; Santiago, V. Synthesis 2016, $48,783$.

(7) Vijayavitthal, T. M.; Gorakshanath, B. S.; Sharad, S. I.; Navnath, C. N.; Panchangam, R.; Vankwala, P. J. Synth. Commun. 2011, 41, 341.

(8) Raj, K.; Vijayavitthal, T. M.; Bhaduri, A. P. Nat. Prod. Lett. 1995, 7, 51.

(9) Process for preparation of 3-[3-(trifluoromethyl)phenyl]propanal (3): To the stirred solution of 3-[3-(trifluoromethyl)phenyl]propan-1-ol (100 g, 0.49 mole) in MDC (3.8 L) was added pyridinium chlorochromate (Corey-Suggs reagent, $137.23 \mathrm{~g}$, 0.64 mole). The resultant reaction mass was stirred, heated at reflux temperature and maintained at the same temperature. Upon completion of reaction (TLC), the reaction mass was filtered. The filtrate was diluted with purified water $(1.0 \mathrm{~L})$ and the layers were separated. The organic layer was washed with $10 \%$ sodium bicarbonate $(1.0 \mathrm{~L})$ solution followed by brine $(1.0$ L) and concentrated under reduced pressure to give an oil (83.0 $\mathrm{g})$. The inorganic residue present in the oil was removed by suspending the oil in n-heptane, with stirring for 20-30 min, filtering the solution through a Hyflow bed and concentration of the mother liquor under reduced pressure provided pure oil of compound 3. Yield $79.0 \mathrm{~g}$ (79.78\%); GC purity $97.5 \%$; MS: $\mathrm{m} / \mathrm{z}=$ $202.10\left[\mathrm{M}^{+}\right] ;{ }^{1} \mathrm{H}$ NMR $\left(\right.$ DMSO-d $\left._{6}\right): \delta=9.82(\mathrm{~s}, 1 \mathrm{H}), 7.47-7.39$ (m, $4 \mathrm{H}, \mathrm{Ar}-\mathrm{H}), 3.03-2.98(\mathrm{t}, 2 \mathrm{H}), 2.84-2.79(\mathrm{t}, 2 \mathrm{H})$.

(10) ICH (International Conference on Harmonization) guideline. http://www.ich.org/products/guidelines/quality/article/quality guidelines.html. Accessed on 18 Oct. 2016. 